\title{
Electrical transport phenomenon in the lead bismuth borate glasses
}

\author{
M. Y. Nadeem and Asim Javed and M. F. Wasiq \\ Physics Department, Bahauddin Zakariya University, Multan, Pakistan, 60800
}

(Received on 31 December, 2008)

\begin{abstract}
Ternary system of lead-bismuth-borate glasses has been fabricated in three different compositions $(\mathrm{PbO}) \mathrm{x} \%$ $-\left(\mathrm{Bi}_{2} \mathrm{O}_{3}\right)(50-\mathrm{x}) \%-\left(\mathrm{B}_{2} \mathrm{O}_{3}\right) 50 \%$ with $\mathrm{x}=5,15$ and 25 using the melt quench technique. The D.C. electrical transport mechanism has been discussed both in the low and high field regions. The coefficients of barrier lowering are calculated based on the Schottky and Poole-Frenkel conduction mechanisms. The refractive index and the high frequency dielectric constants for the prepared glass compositions are evaluated using the optical techniques. The observed decrease in the current level with the increase of the $\mathrm{PbO}$ contents is explained. The high field transport in these glasses is explained in terms of the Jonscher's modified model of the Poole-Frenkel phenomenon.
\end{abstract}

Keywords: Transport mechanisms; Electrical properties; Borate glasses; Pole-Frenkel emission; Jonschers' model.

\section{INTRODUCTION}

Over the past several years, borate glasses have been extensively studied [1] owing to their electrochemical and optical applications as solid-state batteries, optical waveguides and luminescent materials. Some researchers [2-4] have also studied their magnetic and electrical properties. The glassy materials containing lead are more attractive for photonics and optoelectronics applications [1]. PbO can act as both modifier and a glass former. Lead borate glasses have low melting temperatures, wide glass formation regions and good radiation shielding properties [5] and thus have developed technological interests. Bismuth borate glasses have recently attracted great attention [6] since bismuth is the non-toxic among the heaviest elements. Bismuth borate glasses have been investigated with reference to their electrical, optical and thermal properties [7]. Keeping in view the importance of these binary glasses we have prepared and investigated a combination of these groups in the form of a ternary glass system containing the oxides of lead, bismuth and boron. In the present research work we have investigated the conduction in the $(\mathrm{PbO}) \mathrm{x} \%-\left(\mathrm{Bi}_{2} \mathrm{O}_{3}\right)(50-\mathrm{x}) \%-\left(\mathrm{B}_{2} \mathrm{O}_{3}\right) 50 \%$ glass network for the three compositions with $\mathrm{x}=5,15$ and 25 .

\section{EXPERIMENTAL DETAILS}

All the three compositions $(\mathrm{PbO}) \mathrm{x} \%-\left(\mathrm{Bi}_{2} \mathrm{O}_{3}\right)(50-\mathrm{x}) \%-$ $\left(\mathrm{B}_{2} \mathrm{O}_{3}\right) 50 \%$ with $\mathrm{x}=5,15$ and 25 were fabricated using the relevant amounts of $\mathrm{PbO}, \mathrm{Bi}_{2} \mathrm{O}_{3}$ and $\mathrm{B}_{2} \mathrm{O}_{3}$ in the conventional melt quench technique using a platinum crucible. After annealing, the disc shaped samples of ternary glass were polished by grinding them on silicon carbide papers of different grades. For fine polishing, the silicon carbide papers of grades 320-1000 were used. For electrical measurements two-point probe method was employed. These measurements were taken at room temperature. The voltage was applied from 100 to 3000 volts using KEITHLEY 247 High Voltage Supply. The current was measured using KEITHLEY 610C Electrometer which is capable of measuring a current of the order of $10^{-14}$ amperes.

\section{RESULTS AND DISCUSSION}

Figure 1 plots the I-V characteristics of the three fabricated compositions of the lead-bismuth-borate glasses on the logarithmic scale. We observe a transition from the low voltage linear ohmic conduction to the high field assisted barrier conduction following an exponential dependence of current on the applied bias. The ohmic region is attributed to the hoping of the thermally generated carriers (electrons and/or holes) among the localized states which exist within the forbidden band of the non-crystalline solids such as glasses [8].

To investigate the high field conduction mechanism in our glass compositions we plot the logarithmic current against the square root of the applied voltage using the high field data of Figure 1. This plot is given in Figure 2. We notice a decreasing conductivity level with the increasing contents of $\mathrm{PbO}$ of the glass system under study. This can be explained in terms of the increased number of stronger $\mathrm{Pb}-\mathrm{B}$ bonds in the glass structure with the addition of more $\mathrm{PbO}$. The electronegativity difference between $\mathrm{Pb}$ and $\mathrm{B}$ is higher than that between the $\mathrm{Bi}$ and $\mathrm{B}$. Increasing the $\mathrm{PbO}$ contents in lieu of $\mathrm{Bi}_{2} \mathrm{O}_{3}$ increases the number of stronger $\mathrm{Pb}-\mathrm{B}$ bonds over the weaker $\mathrm{Bi}-\mathrm{B}$ bonds in the glass network. The rigidity of the [9] glass thus increases and this in turn causes a decrease in the conductivity level. The straight plots of Figure 2 suggest the mode of electrical conduction in our prepared glass system due to either an electrode limited Schottky phenomenon [10] or the field emission of the carriers from the donor centers known as the bulk-limited Poole-Frenkel effect [11]. To decide between the two, we need to compare the experimental values of the coefficient of the barrier lowering based on the Schottky and Poole-Frenkel equations with the theoretical values of these coefficients evaluated from the high frequency dielectric constant using expressions [10-11];

$$
\beta_{t, s}=\left(e^{3} / 4 \quad o\right)^{1 / 2}
$$

and

$$
\beta_{t, p f}=\left(e^{3} / \quad o\right)^{1 / 2}
$$

The constant is estimated using expression [12] $=n^{2}$ where $\mathrm{n}$ is the refractive index of the prepared glass obtained from the optical re ectance data of each composition [13].

Table 1 lists the values of $\mathrm{n}, \quad \beta_{t, s}$ and $\beta_{t, p f}$ for each prepared composition. The slopes $m_{s}$ of the curves of Figure 2 
Table 1: Coefficient of barrier lowering for the lead-bismuth-borate glass system

\begin{tabular}{|c|c|c|c|c|c|c|}
\hline \multirow[t]{2}{*}{ Composition } & \multirow{2}{*}{$\begin{array}{l}\text { Refractive } \\
\text { Index (n) }\end{array}$} & \multirow{2}{*}{$\begin{array}{l}\text { Dielectric } \\
\text { Constant } \\
(\varepsilon)\end{array}$} & \multicolumn{2}{|l|}{ Theoretical } & \multicolumn{2}{|l|}{ Experimental } \\
\hline & & & $\begin{array}{l}\text { Schottky } \\
\beta_{\mathrm{ts}} \mathrm{X}^{-5} 0^{-5} \\
\left(\mathrm{eVm}^{1 / 2} \mathrm{~V}^{-1 / 2}\right)\end{array}$ & $\begin{array}{l}\text { Poole-Frenkel } \\
\beta_{\mathrm{tPF}} \mathrm{X} 10^{-5} \\
\left(\mathrm{eVm}^{1 / 2} \mathrm{~V}^{-1 / 2}\right)\end{array}$ & $\begin{array}{l}\text { Schottky } \\
\beta_{\mathrm{eS}} \times 10^{-5} \\
\left(\mathrm{eVm}^{1 / 2} \mathrm{~V}^{-1 / 2}\right)\end{array}$ & $\begin{array}{l}\text { Jonscher Poole- } \\
\text { Frenkel Model } \\
\beta_{\mathrm{ej}}{\mathrm{X} 10^{-5}} \\
\left(\mathrm{eVm}^{1 / 2} \mathrm{~V}^{-1 / 2}\right)\end{array}$ \\
\hline $5 \% \mathrm{PbO}+45 \% \mathrm{Bi}_{2} \mathrm{O}_{3}+50 \% \mathrm{~B}_{2} \mathrm{O}_{3}$ & 1.42 & 2.02 & 2.68 & 5.24 & 4.06 & 4.94 \\
\hline $15 \% \mathrm{PbO}+35 \% \mathrm{Bi}_{2} \mathrm{O}_{3}+50 \% \mathrm{~B}_{2} \mathrm{O}_{3}$ & 1.23 & 1.51 & 3.09 & 6.18 & 4.44 & 5.36 \\
\hline $25 \% \mathrm{PbO}+25 \% \mathrm{Bi}_{2} \mathrm{O}_{3}+50 \% \mathrm{~B}_{2} \mathrm{O}_{3}$ & 1.62 & 2.62 & 2.35 & 4.70 & 3.78 & 4.6 \\
\hline
\end{tabular}

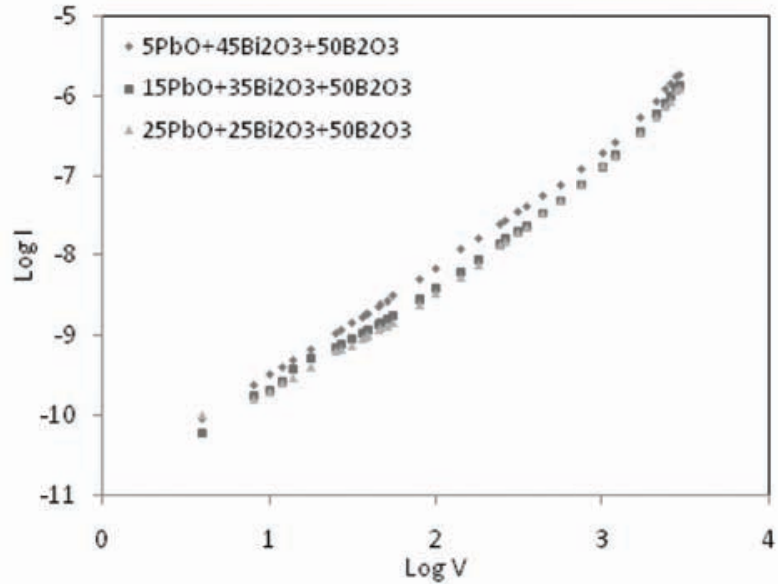

FIG. 1: Plot of current versus voltage on the logarithmic scale

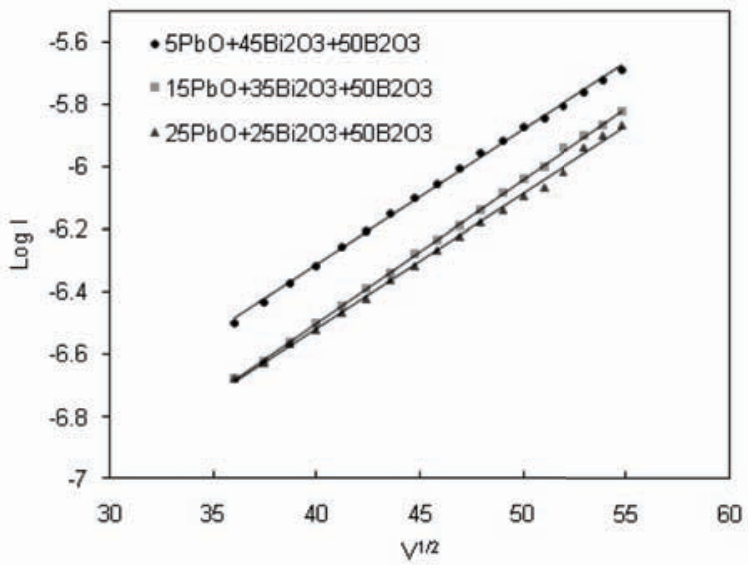

FIG. 2: Log I plotted against $V^{1 / 2}$ for the three compositions (Schottky Model)

are used to obtain the experimental values of $\beta_{t, s}$ using the relation [12].

$$
\beta_{e, s}=m_{s} d^{1 / 2} k T
$$

where $\mathrm{d}$ is the thickness of the glass sample, $\mathrm{k}$ is the Boltzmann constant and $\mathrm{T}$ is the absolute temperature. The values of $\beta_{e, s}$ are given in Table 1 against every composition prepared. Comparing $\beta_{t, s}$ and $\beta_{e, s}$ illustrates a large difference between the two. As per careful calculations we have seen almost 50\% deviation between the theoretical and the experimental values of the Schottky coefficient of barrier lowering.
We can, therefore, discard the possibility of the Schottky conduction in our samples and proceed to discuss the possibility of the Poole-Frenkel conduction as modified by Jonscher [14]. The original Poole-Frenkel I-V equation is [11].

$$
I=I_{0} \operatorname{Vexp}\left[\beta_{p f} V^{1 / 2} / 2 k T\right]
$$

It contains the first power of the applied voltage in the preexponential factor based on the field emission of electrons from the traps in a particular direction. Jonscher [14] extended the Poole-Frenkel theory to a three dimensional well over which all emissions may occur. In one of his modifications the carriers emitted from a trapping site due to the field lowering of barrier are assumed to be re-trapped by a nearest centre downstream. The distance traveled by the carrier before it is re-trapped is independent of the applied field and the current is thus directly proportional to the probability of emission. Jonscher's modified equation is

$$
I=I_{0}\left(k T / e \beta_{p f} V^{1 / 2}\right) \exp \left(e \beta_{p f} V^{1 / 2} / k T\right)
$$

As a result $\log \left(I V^{1 / 2}\right)$ versus $V^{1 / 2}$ plot is required to be linear in the high field region with a slope $m_{j, p f}$ yielding the coefficient of barrier lowering given by

$$
\beta_{p f}=\beta_{j, p f}=m_{j, p f} d^{1 / 2} k T
$$

We have produced these plots in Figure 3 for the three compositions of the glass system being studied. The experimental values $\beta_{j, p f}$ are evaluated as given in the Table 1 . We now see a much better match of the experiment with the theory. The percentage deviation of these experimental values with the theoretical values is reduced to only $1 \%$. Thus the transport phenomenon in the lead bismuth borate glass networks is ascribed to the Jonscher's modified Poole-Frenkel conduction. 


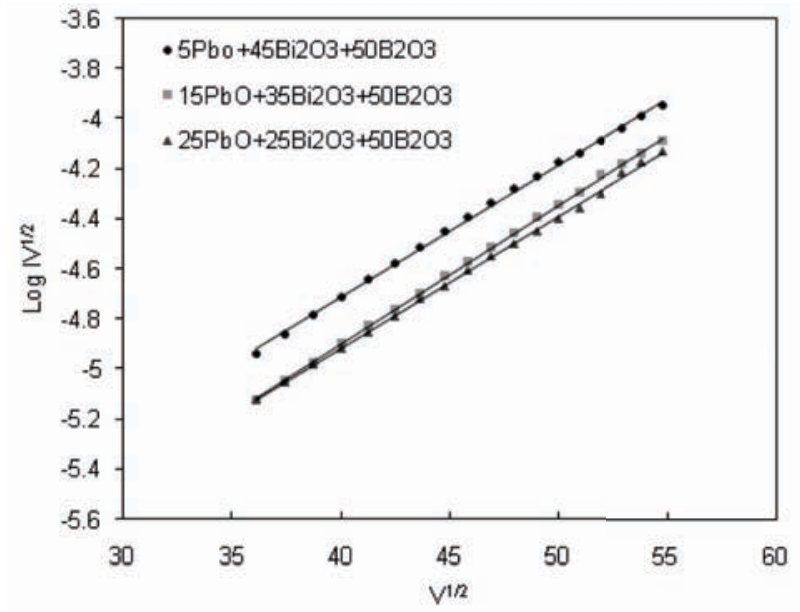

FIG. 3: $\log I V^{1 / 2}$ plotted against $V^{1 / 2}$ (Jonscher's modified PooleFrenkel Model)

[1] W. A Pisarski, Mat. Sci. \& Engg. B 122, 94 (2005)

[2] A. K Arof and S. Radhakrishna, Mat. Sci. Engg.B, 38, 7 (1996)

[3] S. Souto, M. Massot, M. Balkanski and D. Royer, Mat. Sci. Engg. B 64, 33 (1999)

[4] E. Culea, T. Ristoiu and I. Bratu, Mat. Sci. Engg. B 57, 259 (1999)

[5] Z. Pan, S. H. Morgan and B. H. Long, J. Non-Cryst. Sol. 185, $127(1995)$

[6] Y. B. Saddeek, Mat. Chem. \& Phys. 83, 222 (2004)

[7] A. Aagarwal, Radiation Effects and Defects in Solids 158, 793$801(2003)$
[8] J. T. Kerr J. Non-Cryst. Sol. 2, 203 (1970)

[9] N. A. Hegab, J. Phys.D. Phys. 33, 2336 (2002)

[10] W. Schottky, Physik. Z. 15, 872 (1914)

[11] Frenkel J. Phys. Rev. 54, 647 (1938)

[12] L. I. Maissel and R Glang, Handbook of Thin Film Technology 1, 4-29 1970

[13] J. I. Gittleman, E. K. Sichel and Y. Arie, Sol. Energy Matter 1, 93 (1979)

[14] A. K. Jonscher, Thin Solid Films, 1, 213 (1967) 